\title{
PENGUJIAN PERFORMA DAN TINGKAT STRES PADA WEBSITE HOTEL DI KOTA BATAM
}

\author{
Jimmy Adrian ${ }^{1)}$, Jason ${ }^{2)}$, Holong Marisi Simalango ${ }^{3)}$ \\ Teknik Perangkat Lunak, Fakultas Komputer, Universitas Universal \\ Kompleks Maha Vihara Duta Maitreya, Kota Batam, Kepulauan Riau \\ Telp : (0778) 473399 \\ jimmyadrian27799@gmail.com ${ }^{1)}$; jason_guo00@yahoo.com ${ }^{2)}$; simalangoholong@gmail.com ${ }^{3)}$
}

\begin{abstract}
Search for data and information on infrastructure and facilities about a hotel by accessing the hotel's official website. Information in each hotel contains almost the same information, but what differentiates is the impression of efficiency and effective performance, and the level of stress for access quotas. Many Singaporeans and domestic tourists travel to Batam city. This triggers hotel entrepreneurs to maximize service infrastructure and facilities for visitor satisfaction. The methodology used by studying the literature, defining needs, testing web tools, and drawing conclusions on the results of the web tools. The need for web tools for this research is using GTMetrix, Web PageTest, and LoadImpact. The results of this study indicate that the Harris Hotel website is the fastest in loading pages, and the Hotel Harmoni One website is superior in responding to large amounts of access.
\end{abstract}

Keywords: hotel's website, performance testing, stess testing

\begin{abstract}
Abstrak
Pencarian data dan informasi prasarana dan sarana tentang satu hotel dengan mengakses website resmi hotel tersebut. Informasi di setiap hotel berisi informasi yang hampir sama, namun yang membedakan adalah kesan pada performa yang efisiensi dan efektif, dan tingkat stres untuk kuota akses. Banyak warga Singapura dan wisatawan domestik untuk berwisata ke kota Batam. Hal ini memicu untuk Pengusaha hotel memaksimalkan pelayanan prasarana dan sarana demi kepuasan pengunjung. Metodologi yang digunakan dengan studi literatur, defenisi kebutuhan, pengujian webtools, dan penarikan simpulan hasil webtools. Kebutuhan webtools untuk penelitian ini menggunakan GTMetrix, Web PageTest, dan LoadImpact. Hasil penelitian ini menunjukkan bahwa website Hotel Harris adalah yang tercepat dalam memuat halaman, dan website Hotel Harmoni One lebih unggul dalam menanggapi kuota akses dalam jumlah.
\end{abstract}

Kata kunci: website hotel, pengujian performa, pengujian tingkat stress

\section{Pendahuluan}

Penyebaran informasi dengan cara manual dilakukan dengan menyebarkan brosur kertas di tempat umum. Perkembangan teknologi yang semakin pesat juga dimanfaatkan pada penyebaran informasi, yaitu sebagai media penyebaran informasi sangatlah mudah dan cepat, salah satu media tersebut menggunakan website. Informasi yang disebarkan melalui website biasanya adalah informasi promosi tentang jasa ataupun produk yang ditawarkan. Peningkatkan penyebaran informasi melalui website harus berperforma yang menarik, cepat, dan interaktif.

Wisatawan mancanegara maupun domestik jika ingin mengunjungi ke suatu wilayah wisata akan mempersiapkan pada hal akomodasi. Wisatawan akan meninjau informasi dan keadaan akomodasi melalui website dari akomodasi yang dipilih. Website yang memiliki performa dan tampilan yang sangat bagus dapat menambah keyakinan pemilihan informasi akomodasi bagi wisatawan. Performa merupakan salah satu dari proses pengujian aplikasi berbasis web. Performa dapat digunakan mengungkapkan masalah kinerja yang dapat diakibatkan dari rendahnya sumber daya seperti server, bandwith jaringan yang tidak memadai, kapabilitas database yang rendah, kapabilitas sistem operasi yang salah atau lemah, fungsionalitas aplikasi web yang buruk pada saat dirancang, dan masalah perangkat keras maupun lunak lainnya yang berhubungan pada klien-server. Performa ini juga dapat memahami bagaimana sistem merespon saat memuat tampilan.[7]

Penelitian yang dilakukan oleh John Gerdes pada 259 website hotel internasional menggunakan GTMetrix untuk menguji waktu yang diperlukan dalam memuat halaman website pada perangkat desktop dan mobile. Hasil yang didapat yaitu 25 website mendapatkan hasil dibawah 3 detik [1]. Sedangkan Penelitian dalam pengujian oleh Betsy Stringam pada 261 website hotel internasional menggunakan GTMetrix untuk melihat kecepatan dalam memuat halaman pada perangkat desktop dan mobile mendapati hasil bahwa rata-rata diperlukan 11.38 detik. Hanya $25 \%$ dari 261 website hotel memiliki waktu tercepat yaitu 5.6 detik [2]. 
Penelitian untuk artikel ini berfokus pada website di orang sekaligus. Hasilnya berupa waktu yang dibagi kota Batam. Kota batam berseberangan dengan negara menjadi beberapa bagian yaitu waktu saat DNS lookup, Singapura, dan merupakan bagian dari Provinsi waktu koneksi TCP, waktu respon HTTP dan lainnya. Kepulauan Riau. Banyak warga negara Singapura Selain waktu, bandwitch juga diukur selama proses melakukan wisata ke kota batam. Warga Indonesia pengujian website [5].

yang melakukan transit di Negara Singapura, ada

beberapa warga yang menyempatkan diri untuk LoadImpact yaitu alat yang digunakan untuk menguji berwisata di Kota Batam. Fenomena banyaknya wisata beban yang dapat diterima oleh website dan asing dan wisata domestik menjadikan pengusaha menganalisa halaman yang ada pada website. Pengujian hotel-hotel di kota batam meningkatkan pelayanan dibagi menjadi 3 jenis yaitu Fixed, Ramp up dan prasarana dan sarana. Informasi pelayanan prasarana Timeout. Alat ini terbukti ampuh untuk dan sarana ini dapat diakses melalui website resmi hotel mengoptimalkan dan meningkatkan kinerja sebuah tersebut. Pelayanan sarana website ini juga bisa website [6].

dijadikan kesan kepuasan untuk pengguna hotel tersebut.

\subsection{Penyimpulan Data}

Penelitian ini mengkhususkan untuk menilai dan Menerjemahkan hasil pengujian data dan membanding mengukur pelayanan sarana website di area kota batam yang mana website yang berforma terbaik dari tiga khususnya pada website milik hotel Harris dengan website yang dipilih.

domain www.harrishotels.com, SwissBell dengan domain www.swiss-belhotel.com dan hotel Harmoni One dengan domain www.harmonugroup.biz. Tujuannya adalah untuk melihat peforma dan tingkat stress dari ketiga website tersebut yaitu dengan web tools yaitu GTMetrix, Web PageTest, dan LoadImpact.

\section{Metodologi Penelitian}

Metode dalam pencarian data dan pengolah data dalam mendukung menyelesaikan tujuan dari penelitan ini, terdiri dari studi literatur, defenisi kebutuhan, pengujian dengan web tools, dan penyimpulan data.

\subsection{Studi Literatur}

Studi Pustaka atau penelitian kepustaakaan dengan mendapatkan informasi berhubungan dengan pengujian performa dengan cara mempelajari buku-buku dan artikel dari beberapa jurnal yang relevan untuk membantu dalam menyelesaikan penelitian ini.

2.2 Defenisi Kebutuhan

Objek yang dipilih dalam penelitian ini berfokus pada tiga website yaitu website milik hotel Harris dengan domain www.harrishotels.com, SwissBell dengan domain www.swiss-belhotel.com dan hotel Harmoni One dengan domain www.harmonugroup.biz. Kebutuhan webtools untuk penelitian ini menggunakan GTMetrix, Web PageTest, dan LoadImpact.

\subsection{Pengujian dengan webtools}

GTMetrik adalah tools yang berasal dari perusahaan di Kanada yang dirancang menggunakan Google PageSpeed Insights dan YSlow untuk mendapatkan nilai dari performa sebuah website [3]. GTMetrik menguji kecepatan dan efisiensi dan memberikan rekomendasi aksi aksi yang perlu dilakukan untuk meningkatkan kecepatan dan efisiensi dari website yang diuji [4].

WebPageTest adalah tools yang digunakan untuk

\section{Hasil dan Pembahasan}

Meliputi analisis, arsitektur dan metode yang dipakai untuk menyelesaikan permasalahan.

3.1 Pengujian GTMetrix pada Hotel Harris, Hotel SwissBell, dan Hotel Harmoni One

Hasil yang didapat saat melakukan pengujian pada dari website tersebut menggunakan GTMetrix adalah bahwa hotel Harris mendapatkan skor yang lebih baik dibandingkan dengan hotel lainnya. Dapat dilihat pada Gambar 1 bahwa meskipun Harris hotel memiliki size 2.02 MB tetapi skor keseluruhan hotel Harris adalah yang terbaik.

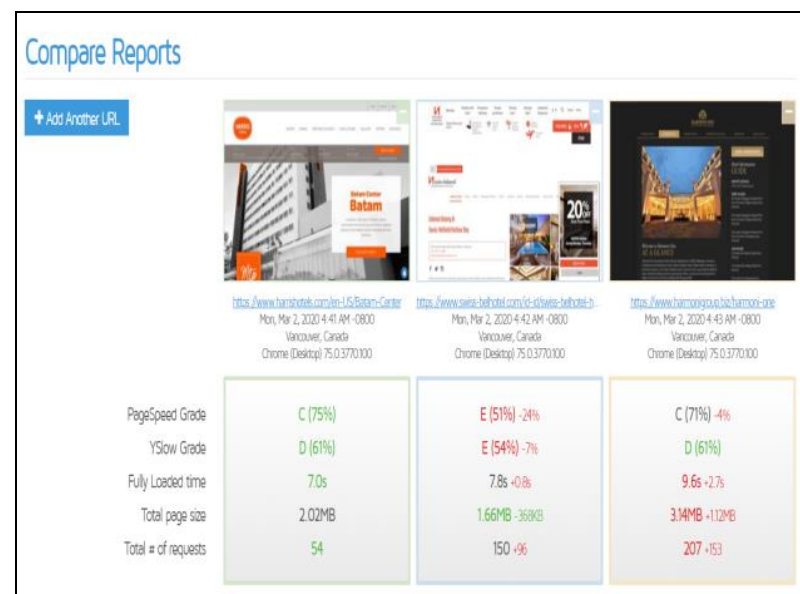

Gambar 1. Hasil Pengujian ketiga website menggunakan GTMetrix

3.2 Pengujian WebPageTest pada Hotel Harris

Pada pengujian menggunakan WebPageTest hasil dari website Hotel Harris tidaklah memuaskan karena rata rata mendapatkan skor $F$ yang terlihat pada Gambar 2. Dapat dilihat pada gambar 3 Hotel Harris memerlukan 7.635 detik untuk memuat penuh website. menguji peforma website jika diakses oleh banyak 


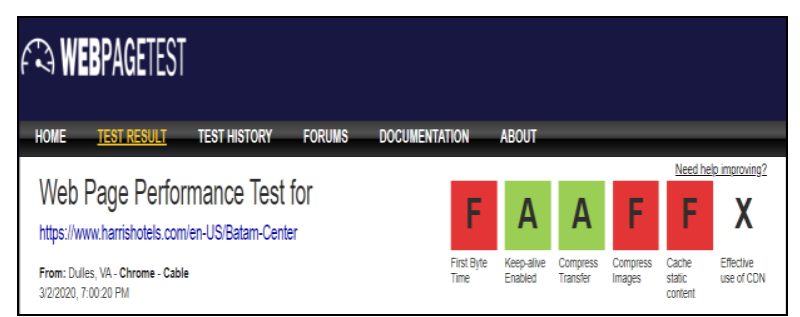

Gambar 2. Hasil Ringkasan dari Pengujian Menggunakan WebPageTest pada Website Hotel Harris

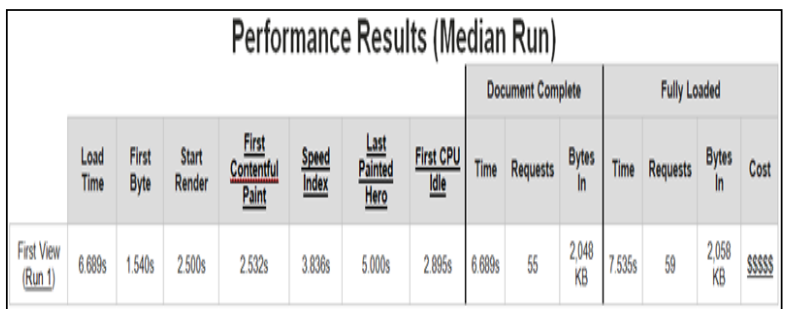

Gambar 3. Hasil Detail dari Pengujian Menggunakan WebPageTest pada Website Hotel Harris

\subsection{Pengujian WebPageTest pada Hotel SwissBell}

Untuk hasil pengujian pada website Hotel SwissBell hasil yang didapat cukup memuaskan karena skor $\mathrm{F}$ yang didapat hanyalah satu yang dapat dilihat pada Gambar 4. Sedangkan waktu yang diperlukan untuk untuk memuat penuh website Hotel SwissBell adalah 7.335 detik yang dapat dilihat pada Gambar 5 .
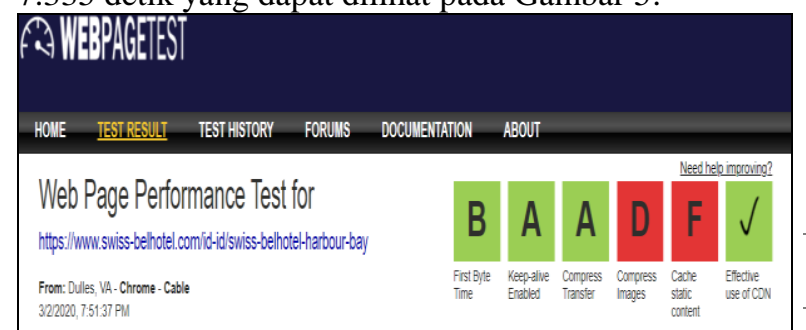

Gambar 4. Hasil Ringkasan dari Pengujian Menggunakan WebPageTest pada Website Hotel SwissBell

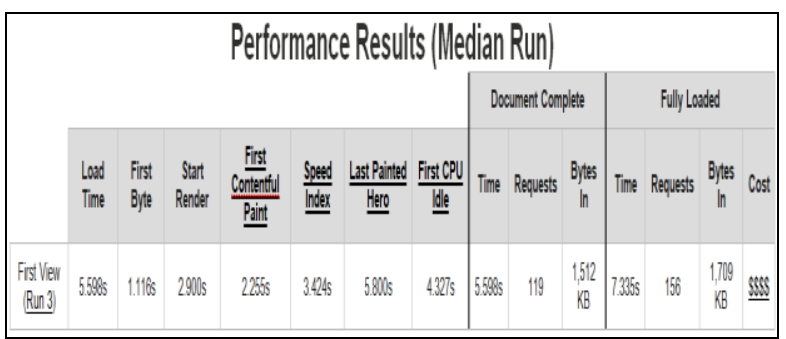

Gambar 5. Hasil Detail dari Pengujian Menggunakan WebPageTest pada Website Hotel SwissBell

3.4 Pengujian pada Hotel Harmoni One

Dan pada pengujian website Hotel Harmoni One cukup memuaskan karena didapat skor rata rata A yang dapat dilihat pada Gambar 6. Sedangkan waktu yang Pada pengujian menggunakan LoadImpact, kami diperlukan untuk memuat halaman website Hotel menggunakan 50 virtual user dalam jangka waktu 2 Harmoni One adalah 12.509 detik yang terlihat pada menit. Hasil yang didapat dari ketiga website tersebut gambar 7.

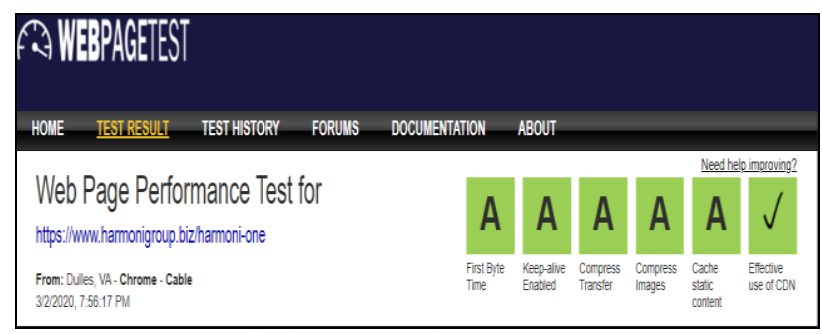

Gambar 6. Hasil Ringkasan dari Pengujian Menggunakan WebPageTest pada Website Hotel Harmoni One

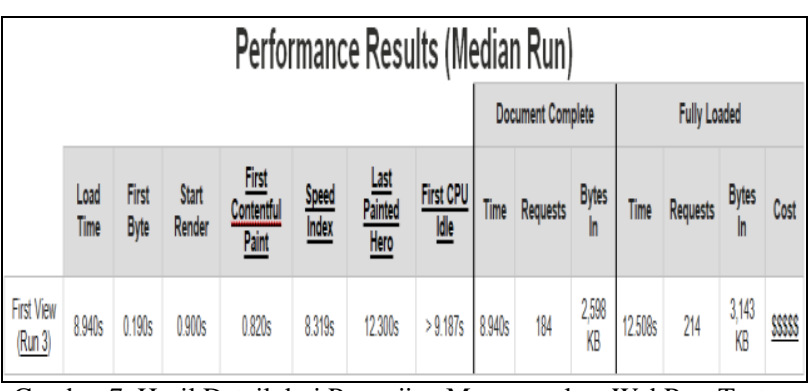

Gambar 7. Hasil Detail dari Pengujian Menggunakan WebPageTest pada Website Hotel Harmoni One.

3.5 Pengujian dengan Load Impact pada Hotel Harris, Hotel SwissBell, dan Hotel Harmoni One

Berdasarkan hasil pengujian diatas dapat dilihat bahwa website pada hotel SwissBell membutuhkan waktu load time yang paling rendah yaitu 5.598 detik. Dan pada website Hotel Harmoni One terlihat bahwa waktu load time yang paling besar. Untuk hasil yang lebih detail dapat dilihat pada Tabel 1 .

Tabel 1. Hasil pengujian website Hotel Hotel Harris, Hotel SwissBell dan Hotel Harmoni One

\begin{tabular}{llll}
\hline Detail Penilaian & $\begin{array}{l}\text { Hotel } \\
\text { Harris }\end{array}$ & $\begin{array}{l}\text { Hotel } \\
\text { SwissBell }\end{array}$ & $\begin{array}{l}\text { Harmoni } \\
\text { One }\end{array}$ \\
\hline Load Time & $6.689 \mathrm{~s}$ & $5.598 \mathrm{~s}$ & $8.940 \mathrm{~s}$ \\
\hline First Byte & $1.540 \mathrm{~s}$ & $1.116 \mathrm{~s}$ & $0.190 \mathrm{~s}$ \\
\hline Start Render & $2.500 \mathrm{~s}$ & $2.900 \mathrm{~s}$ & $0.900 \mathrm{~s}$ \\
\hline $\begin{array}{l}\text { First Contentful } \\
\text { Paint }\end{array}$ & $2.532 \mathrm{~s}$ & $2.255 \mathrm{~s}$ & $0.820 \mathrm{~s}$ \\
\hline Speed Index & $3.836 \mathrm{~s}$ & $3.424 \mathrm{~s}$ & $8.319 \mathrm{~s}$ \\
\hline $\begin{array}{l}\text { Last Painted } \\
\text { Hero }\end{array}$ & $5.000 \mathrm{~s}$ & $5.800 \mathrm{~s}$ & $12.300 \mathrm{~s}$ \\
\hline First CPU Idle & $2.895 \mathrm{~s}$ & $4.327 \mathrm{~s}$ & $>9.187 \mathrm{~s}$ \\
\hline Time & $6.689 \mathrm{~s}$ & $5.598 \mathrm{~s}$ & $8.940 \mathrm{~s}$ \\
\hline Request & 55 & 119 & 184 \\
\hline Bytes In & $2,048 \mathrm{~KB}$ & $1,512 \mathrm{~KB}$ & $2,598 \mathrm{~KB}$ \\
\hline Time & $7.535 \mathrm{~s}$ & $7.335 \mathrm{~s}$ & $12.508 \mathrm{~s}$ \\
\hline Request & 59 & 156 & 214 \\
\hline Bytes In & $2,058 \mathrm{~s}$ & $1,709 \mathrm{~KB}$ & $3,143 \mathrm{~KB}$ \\
\hline Cost & $\$ \$ \$ \$ \$$ & $\$ \$ \$ \$$ & $\$ \$ \$ \$ \$$ \\
\hline
\end{tabular}
adalah website tersebut dapat menahan beban hingga 50 user dalam waktu 2 menit. Dapat dilihat pada Gambar 8 bahwa tidak ada Check failures yang terjadi. 


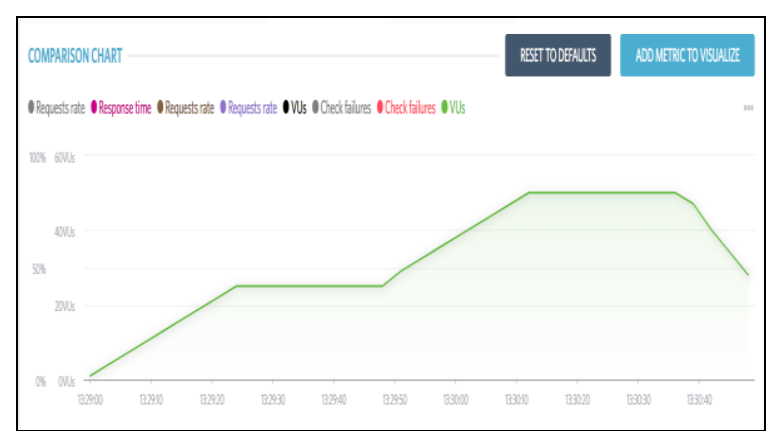

Gambar 8. Hasil pengujian menggunakan LoadImpact.

\section{Kesimpulan}

Pengujian yang dilakan pada website Hotel Harris Hotel, Hotel SwissBell, dan Hotel Harmoni One menggunakan GTMetrix, WebPageTest dan LoadImpact mendapatkan hasil yang terbaik dengan sisi yang berbeda. Hal terbaik seperti website yang memiliki kecepatan dalam memuat halaman adalah website milik Hotel Harris dalam pengujian GTMetrix. Kedua, Website Hotel harmoni One merupakan website yang paling baik dalam menanggani banyak user sekaligus yang terlihat pada pengujian WebPageTest. Dan ketiga website tersebut dapat menanggani 50 user sekaligus dalam waktu 2 menit.

Dapat disimpulkan bahwa website Harris Hotel adalah yang tercepat dalam memuat halaman, sedangkan dalam hal menanggani banyak user sekaligus Hotel Harmoni One adalah yang terbaik. Dan untuk website Hotel SwissBell memiliki skor rata rata dalam kecepatan dan kemampuan menanggapi banyak user sekaligus yang membuat website Hotel SwissBell selalu berada pada posisi kedua. Lambatnya memuat halaman bisa disebabkan beberapa hal, misalnya isi konten yang digunakan di dalam website berkapasitas tinggi. Kecilnya kemampuan menanggapi kuota akses user dapat diatasi dengan meningkat akses server dan storage untuk website tersebut

\section{Ucapan Terima Kasih}

Penulis berterima kasih kepada rekan-rekan mahasiswa dan dosen penulis dari Universitas Universal yang telah memberikan wawasan dan keahlian yang sangat membantu penelitian ini, walaupun mungkin mereka tidak setuju dengan semua interpretasi / kesimpulan dari makalah ini.

\section{Daftar Rujukan}

Arora, I. (2015). A Brief Survey on Web Application Performance Testing Tools Literature Review. International Journal of Latest Trends in Engineering and Technology, 5(3), 367-375.

Asrese, A. S., Sarolahti, P., Boye, M., \& Ott, J. (2016). WePR: A tool for automated web performance measurement. 2016 IEEE Globecom Workshops, GC Wkshps 2016 - Proceedings. https://doi.org/10.1109/GLOCOMW.2016.78490 82

Christina, M. (2019). Pengujian Performa dan Tingkat Stress pada Website Bapenda Jawa Barat, Jawa Tengah, dan Jawa Timur. Media Informatika, 18(2),101-106. https://doi.org/10.37595/mediainfo.v18i2.29

Lestari, W., \& Susanto, A. (2017). Analisis Performa Website ISI Surakarta dan Universitas Diponegoro Menggunakan Automated Software Testing GTmetrix. 2(3), 1-8.

Sommerville, I. (2016). Software Engineering (M. Horton (ed.); 10th ed.). Pearson Education Limited.

Stringam, B., \& Gerdes, J. (2019a). First Impressions in a Mobile World: How Hotel Sites Compare with OTAs, Aggregators and Peer to Peer Accommodations on Website Performance. Journal of Service Science and Management, 12(04), 475-494. https://doi.org/10.4236/jssm.2019.124033

Stringam, B., \& Gerdes, J. (2019b). Service gap in hotel website load performance. International Hospitality Review, 33(1), 16-29. https://doi.org/10.1108/ihr-09-2018-0012 